\title{
I-OnAR: A rule-based machine learning approach for intelligent assessment in an online learning environment
}

\author{
Shaiful Bakhtiar bin Rodzman ${ }^{1}$, Nordin Abu Bakar ${ }^{2}$, Yun-Huoy Choo $^{3}$, Syed Ahmad Aljunid ${ }^{4}$, \\ Normaly Kamal Ismail ${ }^{5}$, Nurazzah Abd Rahman ${ }^{6}$, Marshima Mohd Rosli ${ }^{7}$ \\ ${ }^{1,2,4,5,6,7}$ Faculty of Computer \& Mathematical Sciences, Universiti Teknologi MARA, Shah Alam, Malaysia \\ ${ }^{3}$ Faculty of Information \& Communication Technology, Universiti Teknikal Malaysia Melaka, Malaysia
}

\section{Article Info}

Article history:

Received May 25, 2019

Revised Jul 27, 2019

Accepted Aug 11, 2019

\section{Keywords:}

E-assessment

E-learning

Intelligence

Machine learning

Rule-based method

\begin{abstract}
Intelligent systems are created to automate decision making process that is similar to human intelligence. Incorporating intelligent component has achieved promising results in many applications, including in education. Intelligence modules in a tutoring system would bring the application and its capability closer to a human's ability to serve its human users and to solve problems. However, the majority of the online learning provided in the literature review especially in Malaysia, normally only provide the lecture notes, assignments and tests and rarely suggest or give feedbacks on what the students should study or do next in order to fully understand the subjects. Hence, the researchers propose an online learning environment called Intelligent Online Assessment and Revision (I-OnAR). It facilitates the learning process at multiple learning phases such as test creation, materials revision, feedback for improvement and performance analysis. These components are incorporated into the tutoring system to assist selfpace learning at anytime and anywhere. The intelligent agent uses a Rulebased Machine Learning method for the adaptive capabilities such as automated test creation and feedbacks for improvement. The system has been tested on a group of students and found to be useful to support learning process. The results have shown that $60 \%$ of the subjects' performance have improved with the help of the system. The students were given feedbacks on the topic they did poorly as well as how to improve their performance. This proves that the Intelligent Online Assessment and revision (I-OnAR) can be a useful tool to help online students intelligently, systematically and efficiently. For the future works, the researchers would like to apply the usage of other techniques such as Fuzzy Logic to strengthen the analysis and decision of the current system.
\end{abstract}

Copyright $(5) 2020$ Institute of Advanced Engineering and Science. All rights reserved.

\section{Corresponding Author:}

Shaiful Bakhtiar bin Rodzman,

Faculty of Computer \& Mathematical Sciences,

Universiti Teknologi MARA,

Shah Alam, Selangor Darul Ehsan, Malaysia.

Email: shaiful.bakhtiar.rodzman@gmail.com

\section{INTRODUCTION}

Online learning has gradually became important either as primary or complimentary teaching and learning methods. To date, there are quite limited researches focusing on the student's learning behavior adaptation in online learning done especially in Malaysia. Based on the literature, students' learning styles and behavior in e-learning have significant impacts on the improvement or depletion of students' performance [1]. One example of e-learning related research in Malaysia is Arfan Shahzad et al in [2] who proposes E-Learning Navigation Model Based on Student's Learning Behavior in Universiti Utara Malaysia, 
one of Public University Malaysia, with the objective to improve the student navigation in Online Learning. However, this particular study and the majority of the online learning provided in the literature review normally only provide the lecture notes, assignments and tests and rarely suggest or give feedbacks on what the students should study or do next in order to fully understand the subjects. Adaptivity is important because learners have variety of criteria such as qualities, preferences and learning style, therefore Online learning need to be design to cater all this constraints [3].

Various methods have been applied in e-learning research such as intelligent and adaptive approach. These methods are not new, but have been a constant subject of research and development. An AI-based system such as Intelligent Adaptive Learning Environment (IALE) by Pedrazolli et al in [4] has been developed to identify, monitor and adapt the student's learning path, considering the students actual knowledge, learning habits and preferred learning style. Ueno et al in [5] describes an agent that acquires domain knowledge related to the content from a learning history log database in a learning community and automatically generates motivational messages to the learner. Other online platforms as proposed by Lucila et al in [6] take serious consideration of personalized and self-paced interaction. They take into a consideration the students' learning style and select the suitable teaching strategies that can effectively support the student's learning behavior. In 2016, Lilyana Nacheva-Skopalik et al in [7] propose Intelligent Adaptable e-Assessment for Inclusive e-Learning, the inclusivity means to include all the students especially people with disability. In 2017, Mohammed Hamada et al in [8] proposed the integration of the learning style index into an adaptive and intelligent e-learning system. Hazem Awni et al in [9] proposed the design of a web based intelligent tutoring system for teaching Android Applications Development for the students to overcome the difficulties they face in online learning.

Abhijeet Kumar et al in [10], proposes the adaptive question bank development (AQBDMS), based on certain criteria like Bloom's taxonomy, difficulty level, marking scheme etc., and a management system that aims to generate balanced combination of questions intelligently as per parameter provided by the question paper designer (QPD) and become a great aid to the organisation in effective question modelling and its assessment. Arthur C Graesser et al in [11] proposes ElectronixTutor, an intelligent tutoring system with multiple learning resources for electronics. The latest research we can see is the work of Moiz Uddin Ahmed et al. in [3], that develop A Model of Adaptive E-Learning in an Online Distance Learning Environment which consists three sub models such as content model, learner model and adaptive model, that can improve the knowledge level of the students.

The incorporation of machine learning algorithms into an intelligent agent in a system proved to be vital in optimising the performance such as Hatzilygeroudis et al in [12] and WernhuarTarng et al in [13] that use Rule-based Machine Learning algorithm to facilitate intelligence and adaptivity in their proposed system. Ueno et al in [5] also proposes a computational and learning agent using the constructivist approach, Bayesian Rule in a Learning Management System (LMS) that plays the role of facilitator instead of human teachers. Mike Holmes et al in [14] presents design, development, and evaluation of COMPASS, that uses a novel descriptive analysis of learner behavior, image processing techniques, and artificial neural networks to model and classify authentic comprehension indicative non-verbal behavior. Taekyun Kim et al in [15] proposes Intuitionistic Fuzzy Logic Evaluations for the Analysis of a Student's Knowledge in University eLearning Courses. Jaroslav Melesko et al in [16] proposes semantic clustering and artificial neural network (ANN) based learning analytics software agent for personalised adaptive multi-agent learning system based on learning styles model that requires the use of psychological questionnaire to determine student's learning styles. Marouane Birjali et al in [17] proposes, a novel adaptive e-learning model in Big Data environment to improve the quality of learning process. An efficient learner e-assessment method is provided to determine learners' prerequisites toward the educational resource objectives. The author uses the technique of MapReduce-based Genetic Algorithm to retrieve the FEO based on the learner prerequisites the educational resource objectives.

\section{RESEARCH METHOD}

\subsection{Framework}

In this research, a system with an adaptive learning assessment module using intelligent agent is proposed; and later, I-OnAR is developed. It includes an automated test creation and feedback features. The system will be able to be initiated at any point of time depending on what students have learned: the pages or notes that the student has read that had been retrieved from the navigation retrieval module. The embedded intelligence will improve the system's interaction with the users and offers real help that they seek and respond promptly to the queries when needed. Although it is far away from being a real tutor, teacher or lecturer, the support it gives will benefit the users as if the advice and the feedback come from a real human being. 
The conceptual framework in Figure 1, explains the framework of I-OnAr. I-OnAr features an intelligent agent for the test creation, recommendation and analysis that applies intelligent agent, a Rule-based Machine Learning method for the adaptive learning features called adaptive assessment module. We had applied the Rule-based Machine Learning method on module create test (automated test questions) which generates test questions based on what the user has previously learned (Notes). Evaluation module will evaluate the result and based on the result, the system will generate the recommendation.

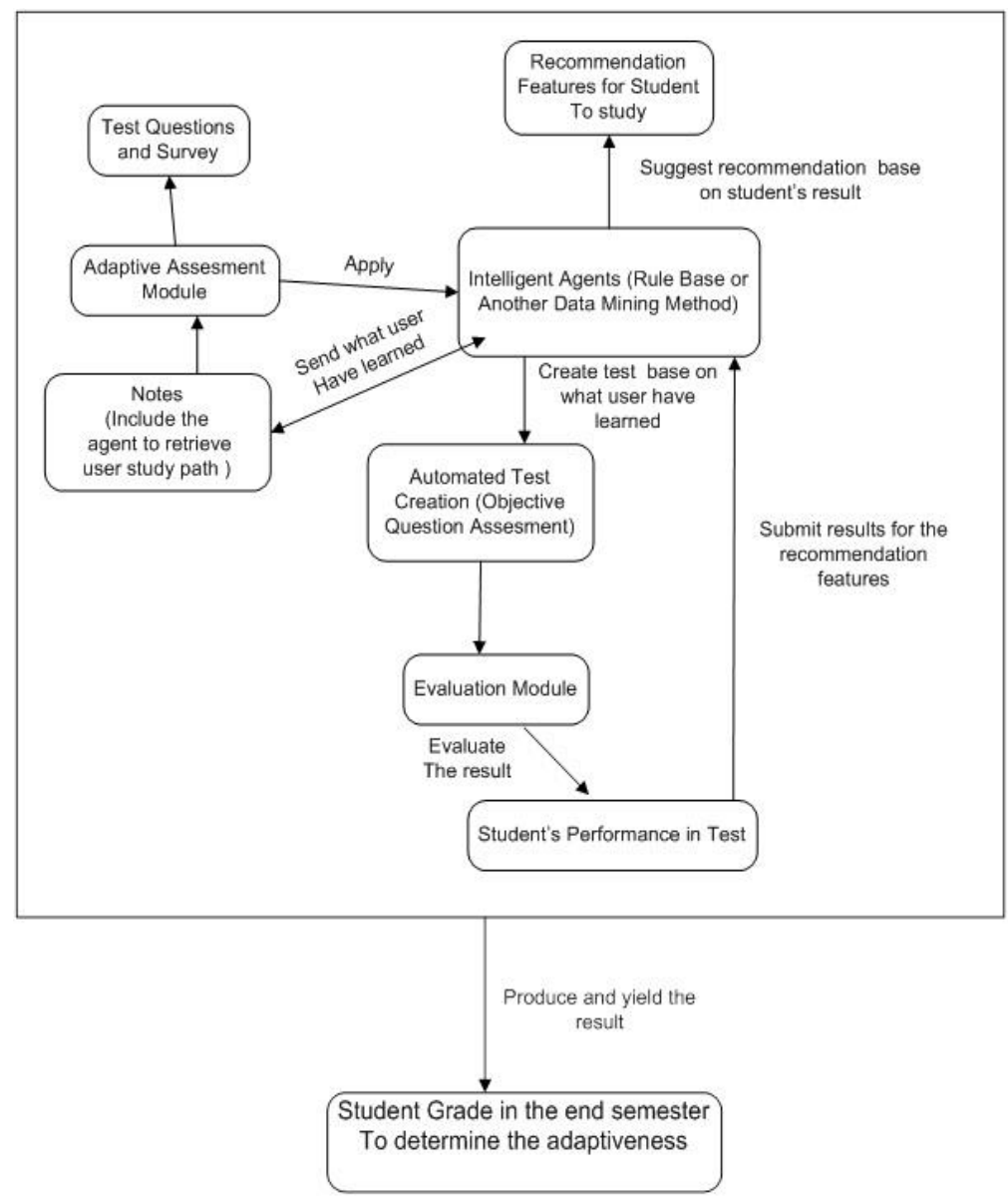

Figure 1. Conceptual Framework of I-OnAr

\subsection{Proposed Method}

The system is particularly has been built as the integration of Intelligent Agent with Rule-based Machine Learning method and Online Learning environment. According to Free Online Encyclopedia Wikipedia that concludes by variety of researches in [18], Rule-based Machine Learning (RBML) is a term in computer science intended to encompass any machine learning method that identifies, learns, or evolves 'rules' to store, manipulate or apply. This method also can be defined by two optional characteristic such as, a while other machine learners that commonly identify a singular model which can be universally applied to any instance in order to make a prediction, the identification and utilization of a set of relational rules of Rule-based Machine Learning are collectively represent the knowledge captured by the system, b) Furthermore, Rule-based Machine Learning is conceptually a type of Rule-based system, it is distinct from traditional Rule-based systems, which are often hand-crafted, and other Rule-based decision makers. This is because Rule-based machine learning applies some form of learning algorithm to automatically identify useful rules, rather than a human needing to apply prior domain knowledge to manually construct rules and curate a rule set. The example of application of Rule-Based in by the work of ZA Bakar et al in [19] and Norzaidah et al. in [20].

The details of application of Rule Based in this particular works will be explained in Table 1 as follows. The Intelligent Agent: The main components of the intelligent agent for this system and Process Flow of Data Collection of I-OnAR are as in: 
Table 1. Component of Intelligent Agent

\begin{tabular}{cc}
\hline Pages & Each question will rely on particular notes that appear in pages \\
\hline Questions & $\begin{array}{c}\text { Each question will carry weights and category of Bloom's Taxonomy } \\
\text { Weightage }\end{array}$ \\
$\begin{array}{c}\text { Each question will carry a weight or mark of either } 1 \text { for easy question or } 2 \text { for difficult } \\
\text { question. We use this mark for the whole question in this system }\end{array}$ \\
Category & $\begin{array}{c}\text { Each question will be categorized according to digital Bloom's Taxonomy which is create, } \\
\text { evaluate, analyze, apply, understand and remember }\end{array}$ \\
\hline
\end{tabular}

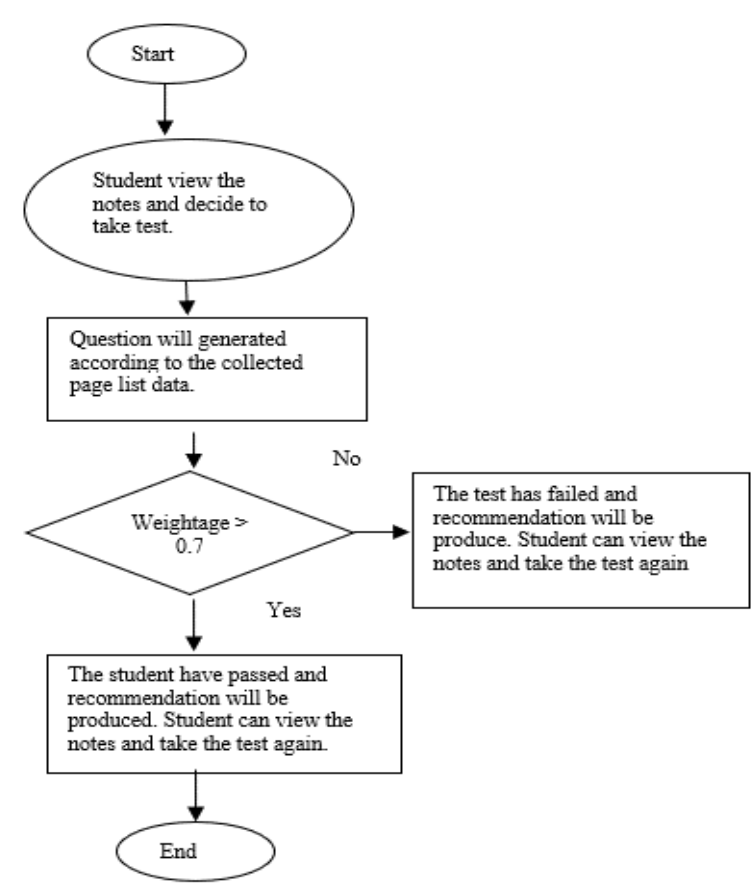

Figure 2. Process flow of data collection of I-OnAR

Data Collection: Process Flow of Data Collection of I-OnAR that represented in Figure 2, will be explained as follow. The page list data will be collected when a student read the page. Questions will be generated according to the collected page list data. In every test, weightage will be recorded from correct answer of the particular question and the total weightage will determine the classification of the user (pass or fail); a pass when the mark exceeds $70 \%$ otherwise a fail will be registered. Those collected more than $70 \%$ of the total weightage will pass the test. This passing mark are agreed by the subject's expert such as Associate Professor Dr. Syed Ahmad Aljunid and Dr. Normaly Kamal Ismail from Faculty of Computer \& Mathematical Sciences, Universiti Teknologi MARA, Shah Alam Malaysia. The system is built by using Java programming language, Java Server Pages and Java Server Faces application and apply the Rule-based Machine Learning method.

Rule-based and Learning Mechanism:

1) weight: sum (weightage from correct question);

2) classification rules:

a) if weight $>0.7=>$ class $=$ pass $\}$

b) If weight $<=0.7 \Rightarrow$ \{ class $=$ fail $\}$

3) pass category: proceed to the next lesson

4) fail category:

a) Recommend user to do topic revision.

b) Display Analysis based on Digital Bloom's Taxonomy and Topic (Weak or Strong).

The system generates the questions based on the pages viewed by the student. Each question will also be categorized according to digital Bloom's Taxonomy, to help the users identify their strengths and weaknesses. The analysis will show the category that has the highest score as well as the lowest. A similar evaluation will also be done on the topic (pages). The analysis and feedback will be shown in the form of graphs and texts. Feedbacks based on the weakest category of Digital's Bloom Taxonomy and the weakest topic are obtained from the student results. The examples of the feedback based on digital Bloom's 
Taxonomy and the example output of feedback in the system are shown in Table 2. Table 2 has shown the example of the feedbacks based on the weakest category of Digital Bloom's Taxonomy and the weakest topic after every test taken by the student.

Table 2. Bloom's Taxonomy Category

\begin{tabular}{cc}
\hline Bloom's Taxonomy category & Feedback (User will be recommended to strengthen the ability as below) \\
\hline Create & $\begin{array}{c}\text { Improve your knowledge by generating or creating new ideas, products, or ways of } \\
\text { viewing things. }\end{array}$ \\
Evaluate & $\begin{array}{c}\text { Justifying a decision, solution, answer or course of action. } \\
\text { Analyze }\end{array}$ \\
Apply & $\begin{array}{c}\text { Breaking information into parts or components to explore or develop or construct } \\
\text { understandings and relationships on what topic that you have learned. }\end{array}$ \\
Understand & Using information, concepts and ideas in another familiar or new or real situation. \\
Remember & Explaining or defining or understanding ideas or concepts.
\end{tabular}

\section{RESULT AND ANALYSIS}

The experiment was conducted on the full-time postgraduate students during their first semester. The students would answer the test based on the chapter in Java Programming. The test consists of 6 topics of this chapter and each topic will contribute 6 questions. Each question will carry the weightage of 1 or 2 depending on the difficulty of the question. Each question will cover one of the categories from digital bloom taxonomy; namely Create, Evaluate, Analyze, Apply, Understand and Remember. The researchers have develop the question bank with the help of subject's expert such as Associate Professor Dr. Syed Ahmad Aljunid and Dr. Normaly Kamal Ismail from Faculty of Computer \& Mathematical Sciences, Universiti Teknologi MARA, Shah Alam Malaysia.

The students were given 2 hours to study using the system without help from books or other materials. The question will be generated by what topic they have read and the amount of time they read the topic. The test will be considered failed if the total weight collected does not exceed $70 \%$; therefore they need to read at least 2 topics to pass the subject. After every test, regardless of their performance, messages will appear and recommend the further actions accordingly. The feedback will be based on the weakest category of Digital's Bloom Taxonomy and the weakest topic as explained above.

The analysis will be generated for students to evaluate their own performance based on both criteria. The student can view the analysis in two ways: the current session analysis or the history analysis. The current session analysis will present the analysis of their performance based on the current login which means it will analyze their performance on the overall student test in their current login session. The historical analysis will present the analysis of their performance on the previous login and include the current login which mean, it will analyze their performance on overall student's test in the system. Both analyses will show the strongest and weakest of category Digital's Bloom Taxonomy and topic that are retrieved from their test result and will be represented in graph and text. The final results and finding of the experiment have been summarized as shown in Table 3 and Table 4.

Table 3 shows positive performance by the students. Generally, all students have done well in the tests. 6 out of 10 students, or $60 \%$ of students have exceeded $50 \%$ collected marks and 2 students out of 10 students have scores that exceeded $80 \%$ collected marks. This result also shows, the all $60 \%$ of students has improved their performance while using this system by achieving more than $50 \%$ collected mark, where the 4 of them have taken the test more than 4 times ( 1 test consist of 6 questions). There are 4 students out of 10 that score below or 50\% collected mark. They have taken the tests less than 4 times; it can be seen by the low amount of answered questions.

Table 3. Sample Results (a)

\begin{tabular}{ccccc}
\hline Student & $\begin{array}{c}\text { Number of Questions Answered } \\
\text { (Multi Choice Questions) }\end{array}$ & Correct & Incorrect & Overall \\
\hline Student 1 & 75 & 65 & 10 & $86.7 \%$ \\
Student 2 & 44 & 40 & 4 & $90.9 \%$ \\
Student 3 & 96 & 60 & 36 & $62.5 \%$ \\
Student 4 & 21 & 8 & 13 & $38 \%$ \\
Student 5 & 10 & 3 & 7 & $30 \%$ \\
Student 6 & 25 & 13 & 12 & $52 \%$ \\
Student 7 & 22 & 8 & 14 & $36.36 \%$ \\
Student 8 & 9 & 5 & 4 & $55.55 \%$ \\
Student 9 & 30 & 11 & 19 & $36.66 \%$ \\
Student 10 & 9 & 5 & 4 & $55.55 \%$ \\
\hline
\end{tabular}




\begin{tabular}{ccccc}
\multicolumn{5}{c}{ Table 4. Sample Results (b) } \\
\hline Student & Strong Category & Weak Category & Strong Topic & Weak Topic \\
\hline Student 1 & Create & Analyze & 1.2 & 1.2 \\
Student 2 & Evaluate & Analyze & 1.1 & 1.6 \\
Student 3 & Create & Understand & 1.1 & 1.1 \\
Student 4 & Create and Evaluate & Analyze & 1.1 and 1.2 & 1.2 \\
Student 5 & Remember & Remember & 1.3 & 1.1 \\
Student 6 & Create & Evaluate & 1.1 & 1.1 \\
Student 7 & Create & Understand and Remember & 1.1 \\
Student 8 & Evaluate & Create and Analyze and Apply & 1.1 & 1.1 \\
Student 9 & Create & and Understand & 1.3 \\
Student 10 & Create and Evaluate and Analyze & Create and Evaluate and Apply & 1.1 & 1.1 \\
\hline
\end{tabular}

In overall, their results have also significantly shown that the performance of the student increases when the number of tests taken by the students is increases. It proves that the feedbacks generated from the system are reliable in helping them increase their performance. Table 4 shows variety of results of the strongest and the weakest category of Digital Bloom's Taxonomy and topics on the subject because the student has each own weakness in certain categories of Digital Bloom's Taxonomy and topics. The lecturer can use I-OnAR to view the overall students' performance in certain categories of Digital Bloom's Taxonomy and topics and utilize the information to improve their students' performance.

Results in Table 4 have shown the feedbacks that had been generated for student after every test, based on their weaknesses on certain categories of Digital Bloom's Taxonomy and subject's topic. The unique part of this system is the feedback that follows the testing phase. Those feedbacks are suggested based on their performance as mapped to the Digital Bloom's Taxonomy and performance of topics in the subject. However, the results can be biased according to the literature review, by the variety of aspects such as degree of the previous knowledge of the sample of students according to Yilun Shang in [21], skill, preferences and also the type of genders [22], and also the small amount of sample size, and it can be the central focus for the future works of researcher to cater on this bias issues. For the future works also, the researchers would like to apply the usage of other techniques such as content-based filtering [23] and Fuzzy Logic to strengthen the analysis and decision of the current system [24] and subsequently improve the application of e-Learning in Malaysia [25].

\section{CONCLUSION}

The researchers presented the implementation of Intelligent Assessment for Online Learning (I-OnAR) that will be a promising tool for online learning environment. It adapts the course materials to the students' need as much as possible based on their profile and knowledge level. The system uses the student's knowledge level to generate the questions by capturing what the student has learnt so far. After solving the questions, the assessment part evaluates the performance of the student and gives the feedback to the student to improve their performance. It will help the student to recognize their strengths and weaknesses. The feedbacks are based on how much their correct answers cover to the categories of digital Bloom's taxonomy.

The target of this system is to develop a successful system to help lecturers and students in online learning assessment. The lecturers don't need to guide a student and evaluate their students' performance and the students also can improve their performance from the guidance given by the system. The results have shown that $60 \%$ of the students have improved their performance in the selected subject using the system. This shows that this system has a potential to establish a new platform for the online learning to grow and prosper further in the future. In the future, the researchers would like to try new techniques such as Fuzzy Logic into the system as well as several new features to enhance the evaluation.

\section{ACKNOWLEDGEMENTS}

This research is funded by the Ministry of Education (MOE) Malaysia under FRGS Research Grant at Universiti Teknologi MARA, Shah Alam (600-IRMI/FRGS 5/3 (021/2017)). 


\section{REFERENCES}

[1] Amira Fatiha Baharudin, et al., "Behavioral Tracking in E-Learning by Using Learning Styles Approach," Indonesian Journal of Electrical Engineering and Computer Science, vol. 8, No. 1, pp. 17-26, doi: 10.11591/ijeecs.v8.i1., October 2017.

[2] Arfan Shahzad, et al., "E-Learning Navigation Model Based on Student's Learning Behavior: Case Study in UUM," International Journal of Business and Social Science, vol. 5, No. 5(1), April 2014.

[3] Moiz Uddin Ahmed, et al., "A Model Of Adaptive E-Learning in an ODL Environment," Mehran University Research Journal Of Engineering \& Technology, vol. 37, No. 2, 367-382, April 2018 P-Issn: 0254-7821, E-Issn: 2413-7219 Doi: 10.22581/Muet1982.1802.1

[4] Attilio Pedrazzoli, M and Luisa Dall'Acqua, "An Artificial Intelligence-Multi Agent based Intelligent Adaptive Learning Environment (IALE)," in Proc. the World Congress on Engineering and Computer Science, San Francisco, USA, vol. 1, 2009.

[5] Ueno, M., "Bayesian Agent in e-Learning," in Proc. Seventh IEEE International Conference on Advanced Learning Technologies (ICALT 2007), pp. 282-284, 2007.

[6] María Lucila Morales-Rodríguez, et al., "Architecture for an Intelligent Tutoring System that considers learning styles," Research in Computing Science 2012.

[7] Lilyana Nacheva-Skopalik and Steve Green, "Intelligent Adaptable e-Assessment for Inclusive e-Learning," International Journal of Web-Based Learning and Teaching Technologies (IJWLTT), vol.11, no. 1, doi: 10.4018/IJWLTT.2016010102, pp. 14, 2016.

[8] Mohammed Hamada and Mohamed Hassan, "An Enhanced Learning Style Index: Implementation and Integration into an Intelligent and Adaptive e-Learning System," Eurasia Journal of Mathematics, Science and Technology Education, vol. 13, 2017.

[9] Hazem Awni Al Rekhawi and Samy S. Abu Naser, "An Intelligent Tutoring System for Learning Android Applications UI Development," International Journal of Engineering and Information Systems (IJEAIS), vol. 2, no. 1, pp. 1-14.

[10] Abhijeet Kumar, et al., "Effective question modelling and intelligent question bank storage engine: an adaptive graph based approach," International Journal of Knowledge and Learning, vol. 12, no.3, 2018.

[11] Graesser, Arthur C., et al., "ElectronixTutor: an intelligent tutoring system with multiple learning resources for electronics," International Journal of STEM Education, pp. 2196-7822, 2018.

[12] Ioannis Hatzilygeroudis, et al., "Knowledge-Based Adaptive Assessment in a Web-Based Intelligent Educational System," in Proc. Sixth International Conference on Advanced Learning Technologies (ICALT'06), 0-7695-2632-2/06 IEEE, 2006.

[13] WernhuarTarng, et al., "An Adaptive Web-Based Learning System For The Scientific Concepts Of Water Cycle In Primary Schools," Journal Advanced Technology for Learning archive, vol. 4, no. 2, pp. 74-84, March 2007.

[14] M. Holmes, "Near Real-Time Comprehension Classification with Artificial Neural Networks: Decoding e-Learner Non-Verbal Behavior," IEEE Transactions on Learning Technologies, vol. 11, No. 1, doi: 10.1109/TLT.2017.2754497, pp. 5-12, 1 Jan.-March 2018.

[15] Taekyun Kim, et al., "Interval Valued Intuitionistic Fuzzy Evaluations for Analysis of a Student's Knowledge in University e-Learning Courses, " International Journal of Fuzzy Logic and Intelligent Systems, vol. 18, no. 3, pp. 190-195, 2018.

[16] Jaroslav Melesko and Eugenijus Kurilovas, "Semantic Technologies in e-Learning: Learning Analytics and Artificial Neural Networks in Personalised Learning Systems," in Proc. 8th International Conference on Web Intelligence, Mining and Semantics Article, No. 34 Novi Sad, Serbia-June 25 - 27, 2018 ACM New York, NY, USA, ISBN: 978-1-4503-5489-9.

[17] Marouane Birjali and Mohammed Erritali, "A novel adaptive e-learning model based on Big Data by using competence-based knowledge and social learner activities," Applied Soft Computing, doi: 10.1016/j.asoc.2018.04.030, April 2018.

[18] "Rule-based machine learning", WIKIPEDIA.org. https://en.wikipedia.org/wiki/Rule-based_machine_learning. (accessed Mei 2, 2019).

[19] ZA Bakar, et al., "Detection of Compound Word with Combination Noun and Adjective using Rule Based Technique in Malay Standard Document," Journal of Telecommunication, Electronic and Computer Engineering (JTEC), vol. 9, no, 3-5, pp. 129-134

[20] Norzaidah Md Noh, et al., "Intelligent Tutoring System Using Rule-Based and Case-Based: A Comparison," Procedia - Social and Behavioral Sciences, vol, 67, pp. 454-463.

[21] Y. Shang, "Subgraph Robustness of Complex Networks Under Attacks," IEEE Transactions on Systems, Man, and Cybernetics: Systems, vol. 49, no. 4, pp. 821-832, April 2019. doi: 10.1109/TSMC.2017.2733545

[22] Marshima Mohd Rosli et al., "Undergraduate student preference activities and sources to learn programming," in 2010 2nd International Congress on Engineering Education, pp. 47-51, Publisher, IEEE, Publication date 2010/12/8 Conference.

[23] NL Adam, et al., "Personalized recommender system for calculus using content-based filtering approach," International Journal of Engineering and Technology (UAE), vol. 7, no. 3, pp. 110-113.

[24] Shaiful Bakhtiar bin Rodzman, et al., "Domain specific concept ontologies and text summarization as hierarchical fuzzy logic ranking indicator on malay text corpus," Indonesian Journal of Electrical Engineering and Computer Science, vol 15, No 3 September 2019.

[25] Anuwar, Ali, Prof Tan Sri Datuk., "Issues and challenges in implementing e-learning in Malaysia," Universiti Terbuka Malaysia (UNITEM) Kuala Lumpur, Malaysia, 2004. 


\section{BIOGRAPHIES OF AUTHORS}

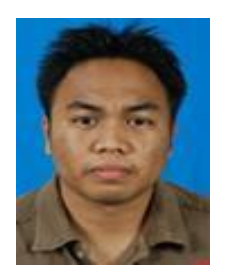

Shaiful Bakhtiar bin Rodzman (MSc), a Ph.D. student and Research Assistant at Computer Science Departments of Faculty of Computer and Mathematical Sciences in UiTM, Shah Alam. His research interests focus on Ranking Function of the Malay Information Retrieval, Malay Document Retrieval Framework and the Fuzzy Logic. He has joined various product innovation competitions in the field of Financial and Information Retrieval. He had worked for six years in Financial Institution, Statistic and the Software company.

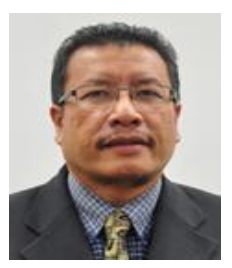

Nordin Abu Bakar (PhD), is an Associate Professor at Computer Science Departments of Faculty Computer and Mathematical Sciences in UiTM, Shah Alam. His research focuses on Software Engineering, Evolutionary Computation, Genetic Algorithms, Islamic Finance, Computer Science Education and Machine Learning.

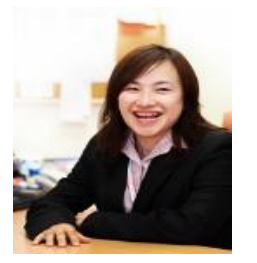

Choo Yun Huoy (PhD), is an Associate Professor at Department of Intelligent Computing and Analytics of Faculty of Information \& Communication Technology, Universiti Teknikal Malaysia Melaka. Her research focuses on Data Mining, Soft Computing, Feature Selection, Association Rules Mining and Feature Optimization.

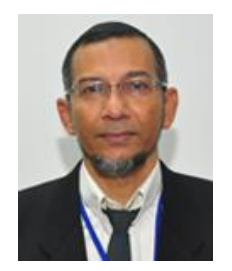

Syed Ahmad Sheikh Aljunid (PhD), is Associate Professor at Computer Science Department, Faculty of Computer and Mathematical Sciences in UiTM, Shah Alam. His research work focuses on Software Development, Mobile Apps development, Ontology, Software Testing, Programming and Penetration Testing.

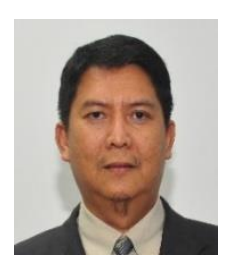

Normaly Kamal Ismail (PhD), is a Senior Lecturer at Computer Science Departments of Faculty Computer and Mathematical Sciences in UiTM, Shah Alam. His research focuses on Malay Information Retrieval, Mobile Apps development, Text Processing and Visualization, Sentiment Analysis, Ontology and Penetration Testing. He currently serves as President of Universiti TeknologiMARA Academic Association and Deputy President of Malaysia Academic Association Congress (MAAC).

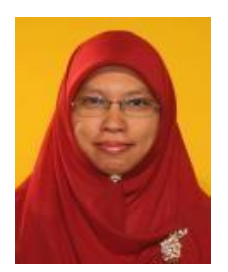

Nurazzah Abdul Rahman (PhD), is an Associate Professor at Computer Science Department, Faculty of Computer and Mathematical Sciences in UiTM, Shah Alam. Her main research area is Information Retrieval (IR), focuses in Malay Text IR specifically in Malay Translated Hadith Text corpus and Information Extraction. She is also an active member of IEEE CS Malaysia Chapter and the Society of Information Retrieval and Knowledge Management (PECAMP).

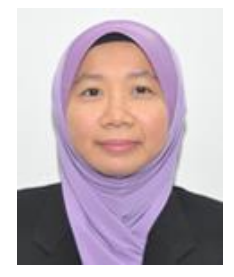

Marshima Mohd Rosli (PhD), is a Senior Lecturer at Computer Science Department, Faculty of Computer and Mathematical Sciences in UiTM, Shah Alam. Her main research area is Software Engineering, particularly empirical software engineering (ESE), web technology engineering, software measurement and data quality. Her also have been involved in studies that investigated the quality of data in software engineering data sets. 